\title{
Direito Ambiental no Brasil e nos Estados
}

\author{
Unidos $^{1}$
}

\section{Antônio Herman Benjamin Visiting Professor The University of Texas at Austin School of Law}

O direito ambiental é como uma encruzilhada de disciplinas jurídicas. Ele quer ser uma disciplina jurídica autônoma, ainda que em comunicação permanente, ativa com outras disciplinas jurídicas. É como uma "esponja" que absorve as outras disciplinas, transformando tais instrumentos, institutos e princípios jurídicos e exportando-os para as outras disciplinas jurídicas.

Agora vamos estudar as influências do direito constitucional no direito ambiental e, mais recentemente, ao reverso, de modo que o direito ambiental atua modelando algumas estruturas básicas do direito constitucional. Veremos isso claramente no direito administrativo, especialmente nos Estados Unidos, onde o direito administrativo é uma criação do direito ambiental, embora não possamos dizer o mesmo do direito administrativo continental europeu, uma criação do séc. XIX.

$O$ direito ambiental transforma profundamente o direito de propriedade ${ }^{2}$. $O$ renascimento dos estudos da disciplina da propriedade, como vemos atualmente, ocorre e só ocorre por conta das exigências próprias da proteção ambiental. O direito penal é um antes do direito ambiental e outro depois do direito ambiental. O processo civil foi

\footnotetext{
1 Palestra proferida no curso Introdução ao Direito Norte-americano, em 21 de agosto de 2001, degravada por Fernanda Nunes Barbosa (PPGDir/UFRGS) e revisada por Marcelo Leal (PPGDir/ UFRGS).

2 Como escrevemos em Introdução ao Direito Ambiental Brasileiro, estudo apresentado, originalmente, no Fórum Lusófono sobre Redação Normativa e Direito do Ambiente, Praia, Cabo Verde, 23-27 de novembro de 1998, sob os auspicios da IUCN e de sua Comissão de Direito Ambiental, já virou lugar comum apregoar-se que o direito de propriedade, nas ordens constitucionais modernas e democráticas, tem (ou deve ter) sempre um conteúdo social, que se expressa, em linguagem jurídica, pela fórmula, universalmente adotada, da função social do domínio (e da posse). Um instituto gerido na conviç̧ão, hoje incontestável, de que a propriedade, mesmo quando privatizada em um dominus particular, deve operar, sem exceção, em favor do interesse coletivo.
} 
profundamente modificado pela necessidade de ampliar-se a legitimação para agir e pela necessidade de remodelar a coisa julgada. Enfim, todas as disciplinas jurídicas recebem, de certa maneira, o contato - muitas vezes até radical - do direito ambiental.

Em uma aula de trinta minutos não há condições de aprofundar-se o quadro comparativo entre o direito ambiental brasileiro e o norte-americano. $O$ que iremos fazer é um vôo panorâmico, buscando os aspectos mais interessantes - nem sempre os mais importantes - de tal comparação.

Começamos com o contexto histórico. Nos Estados Unidos, costumamos dizer que o direito ambiental maduro, como conhecemos hoje, é produto do final da década de 60 e do início da década de 70. Do ponto de vista da gênese da disciplina nos Estados Unidos, notaremos uma característica no quadro da própria formação desse ramo do direito. Nos Estados Unidos, o direito ambiental ocorre como produto do direito nativo, com pouca influência do direito internacional. É um direito chamado autóctone, muito embora acredite que tal seja uma impropriedade, porquanto os sistemas jurídicos estão em constante comunicação, mesmo quando não percebemos ou não gostamos - como é o caso do direito norte-americano. Os doutrinadores americanos criticam muito os franceses, que nem sequer citam autores estrangeiros e, quando citam, só o fazem quando escritos em francês. Os americanos não citam também estrangeiros, por não sentirem a necessidade de citá-los em disciplinas novas, pois acreditam que seus trabalhos sejam esforços secundários, derivados do direito norteamericano - o que não deixa, de certa maneira, de ser verdade. Afinal, no direito ambiental e do consumidor europeus, se selecionarmos as Diretivas da União Européia, a exemplo da Diretiva da Responsabilidade do Fabricante de 1995, veremos um belíssimo sumário do regime jurídico norte-americano naquela matéria. Ainda, se analisarmos a Diretiva da União Européia no âmbito de estudos de impacto ambiental, veremos um resumo muito bem elaborado, aperfeiçoado e modernizadó dos estudos acerca do impacto ambiental americano, o que justificaria, por assim dizer, o traço afrancesado do direito norte-americano, que insiste em ignorar o seu entorno. Isso, no entanto, está mudando, tendo em vista a internacionalização a respeito de algumas disciplinas jurídicas, a exemplo do direito ambiental.

No Brasil, temos um direito ambiental que aparece mais tarde - mas não muito -, efetivamente a partir da Lei 6.938, de 1981, chamada exatamente com o nome da legislação que a inspirou, a Lei da Política Nacional de Meio Ambiente dos EUA, National Environment Policy Act, de 1970. Todavia, nosso direito ambiental é de conteúdo e raízes bem mais antigas. Já na década de 30 legislávamos no Brasil sobre florestas, sobre fauna, sendo que nosso Código Florestal atual, de 1965, é tão moderno, que muitos de seus institutos continuam "dormindo em berço esplêndido".

A lei de proteção à fauna é um dos regulamentos jurídicos que tratam de aspectos de direito ambiental mais adiantados do mundo, já de 1977. O que ocorre em 1981, com a promulgação da lei, é que deixamos de tratar do todo, que é o meio ambiente, através de seus elementos, quais sejam, água, solo, ar, fauna, flora. A partir daí, passamos 
a tratar o meio ambiente como tal, reconhecendo-o no âmbito do ordenamento como bem jurídico dotado de autonomia ${ }^{3}$.

Ainda nesta parte histórica, tanto nos EUA como no Brasil fazemos a distinção entre direito ambiental verde (o direito ambiental da natureza) e marrom (o direito do controle da poluição). Quanto ao direito de controle da poluição, nos dois países a regulação jurídica é produto de acidentes ambientais extremamente sérios. Nos EUA, isso ocorreu com os rios que pegaram fogo em Cleveland, Ohio, com o desastre do Lloyd Channel, que levou, neste caso, à aprovação da lei do Super Fund (Super Fundo).

${ }^{3}$ Conforme referimos em Introdução ao Direito Ambiental Brasileiro, inicialmente, a questão ambiental, no periodo colonial, imperial e republicano, este até a década de 60 do atual século, juridicamente não existia, caracterizadas as iniciativas pontuais e raras do Poder Público mais como conservação do que propriamente como preservação. Esta, pois, a fase da exploração desregrada ou do laissez-faire ambiental, onde a conquista de novas fronteiras (agrícolas, pecuárias e minerárias) era tudo que importava na relação homem-natureza. Tinha na omissão legislativa seu traço preponderante, relegando-se eventuais conflitos de cunho ambiental quando muito ao sabor do tratamento pulverizado, assistemático e privatístico dos direitos de vizinhança. Num segundo momento, a fase fragmentária, o legislador - agora já preocupado com largas categorias de recursos naturais mas ainda não com o meio ambiente em si mesmo considerado - impôs controles legais às atividades exploratórias. A recepção incipiente da degradação do meio ambiente pelo ordenamento operava, no plano ético, pelo utilitarismo (tutelando somente aquilo que tivesse interesse econômico) e, no terreno formal, pelo reducionismo, tanto do objeto (o fatiamento do meio ambiente, a ele ainda se negando, holisticamente, uma identidade jurídica própria), como, até em conseqüência, do aparato legislativo. Encaixam-se ai o Código Florestal, de 1965; os Códigos de Caça, de Pesca e de Mineração, todos de 1967; a Lei da Responsabilidade por Danos Nucleares, de 1977; a Lei do Zoneamento Industrial nas Áreas Críticas de Poluição, de 1980 (embora traga ela elementos próprios da terceira fase); e a Lei de Agrotóxicos, de 1989. Ainda nesse periodo, pelo Decreto Federal n. 73.030, de 30.10.73, foi criada a SEMA - Secretaria Especial do Meio Ambiente, subordinada ao Ministério do Interior, o que não deixa de ser curioso, já que temos aí um precedente em que a estrutura administrativa, mesmo que em caráter precursor, adianta-se ao quadro normativo especializado, que só apareceria mais adiante. Finalmente, indicando uma (re)orientação radical de rumo, aparece a Lei da Política Nacional do Meio Ambiente (1981), dando início à fase holística, onde o ambiente passa a ser protegido de maneira integral, vale dizer, como sistema ecológico integrado (resguardamse as partes a partir do todo), com autonomia valorativa (é, em si mesmo, bem jurídico) e com garantias de implementação (= facilitação do acesso à justiça). Só com a Lei n. 6938/81, portanto, é que verdadeiramente começa a proteção ambiental como tal no Brasil, indo o legislador além da tutela dispersa, que caracterizava o modelo fragmentário até então vigente (assegura-se o todo a partir das partes). Afastando-se da metodologia de seus antecessores legislativos, a lei não só estabeleceu os princípios, objetivos e instrumentos da Politica Nacional do Meio Ambiente, como ainda incorporou, de vez, no ordenamento jurídico brasileiro o Estudo de Impacto Ambiental, instituindo, ademais, um regime de responsabilidade civil objetiva para o dano ambiental, sem falar que the coube conferir ao Ministério Público, pela primeira vez, legitimação para agir nessa matéria. Com idêntica filiação holística e fechando o círculo da regulação legal (que agora é administrativa, civil e penal), é aprovada, em 1998, a Lei dos Crimes contra o Meio Ambiente. 
No Brasil, todos sabemos que a Lei da Política Nacional de Proteção ao Meio Ambiente de 1981 foi uma resposta direta aos desastres ambientais de Cubatão, o chamado Vale da Morté.

Passemos, agora, à análise constitucional do meio ambiente. No Brasil, a partir de 1985, temos um capítulo inteiro tratando sobre direito ambiental, de grande complexidade e riqueza substantiva, mas também instrumental, que cria, pela primeira vez no Brasil, o chamado Direito a um Meio Ambiente Equilibrado. Além disso, tal sistema constitucional prevê, expressamente, a função social da propriedade ${ }^{5}$, estabelecendo, como fundamento da intervenção da União nos Estados e dos Estados nos Municípios, o Poder de Polícia, (Police Power).

Nos EUA, não há proteção constitucional ao meio ambiente ${ }^{6}$. Aliás, o que encontramos na Constituição americana é um vastíssimo e rigoroso tratamento do direito de propriedade privada. Não há uma palavra sobre deveres do Estado, sobre a aplicabilidade de direitos implícitos em relação ạ terceiros, enfim, é uma Constituição em que os direitos e obrigações operam entre indivíduos e Estado.

\footnotetext{
${ }^{4}$ Quando a poluição industrial era tema quase diário dos principais jornais brasileiros e chamava a atenção, pela sua gravidade, até da imprensa estrangeira (a cidade de Cubatão, no Estado de São Paulo, tornou-se caso emblemático, sendo seu complexo petroquimico apelidado de "Vale da Morte"), o Congresso Nacional, por iniciativa do Poder Executivo, trouxe para si a questão, visando dar um basta na situação que, então, mostrava-se insustentável. Foi nesse clima de desastre ambiental que entrou em vigor a Lei n. $6.803 / 80$, promulgada no auge da controvérsia de cidade de Cubatão. Tal texto legal, de caráter bem limitado, traça diretrizes básicas para o zoneamento industrial em áreas criticas de poluição, parcelando o solo em três modalidades de áreas: a) zonas de uso estritamente industrial; b) zonas de uso predominantemente industrial; e, c) zonas de uso diversificado. Por outro critério, as zonas deverão ser classificadas em não-saturadas, em vias de saturação e saturadas. Nos casos de indústrias altamente poluidoras, a lei prevê inclusive a possibilidade de relocalização das unidades produtivas, cabivel quando preenchidos certos requisitos: a) gravidade da poluição; b) ocorrência em zona que não seja de uso estritamente industrial; c) insuficiência dos equipamentos de controle de emissões instalados pela empresa. A relocalização é determinada pelo Poder Público, às expensas do poluidor, implicando na transferência da unidade para outra área. Logo em seguida, o Congresso editou a Lei n. 6.938/81 (Lei da Política Nacional do Meio Ambiente), esta, sim, estatuto jurídico ambicioso e de grande alcance. Um poderoso texto legal que, dogmaticamente falando, instala um novo paradigma juridico no relacionamento homem-natureza. ${ }^{5}$ Salientamos em nosso estudo Introdução ao Direito Ambiental Brasileiro que o direito ao ambiente ecologicamente equilibrado não se encontra isolado no corpo constitucional. Não é norma solitária, perdida no oceano dos comandos da Constituição. Ao revés, é direito sintonizado e entrelaçado com outros institutos incorporados pelo constituinte. Um deles é a função social da propriedade, já reconhecida em constituições anteriores e que podemos denominar de "genérica", ponto de partida usado pelo regime de 1988 para inovar com a função sócio-ambiental da propriedade.

${ }^{6} \mathrm{Não}$ obstante a constatação de que, ainda hoje, importantes sistemas jurídicos, ai se incluindo os Estados Unidos, protegem o ambiente sem contar com apoio expresso ou direto na Constituição, razōes várias recomendam a constitucionalização da proteção ao meio ambiente, podendo ser essa considerada uma tendência mundial, o que certamente foi percebido pelo constituinte brasileiro de 1988.
} 
Nossa Constituição, de caráter "welfarista" cria, a um só tempo, obrigações e direitos no trato entre os indivíduos e o Estado, mas também no trato dos indivíduos entre si. Afinal, ela reconhece não apenas indivíduos, mas também coletividades, instituições tais como a família, a cultura e a educação.

No caso dos EUA, há uma ausência total da proteção ao meio ambiente em âmbito federal. A partir de 1968 e início da década de 70, nos EUA, tentou-se fazer alterações na Constituição, para que houvesse previsão expressa de proteção ao meio ambiente. Alguns Estados, por sua vez, dispõem expressamente sobre a proteção ao meio ambiente, como Illinois, California, Pennsylvania e Michigan; dispositivos estes que não tiveram, contudo, utilização concreta em processos judiciais. Importante mencionar que não é o Police Power (Poder de Polícia) que fundamenta a intervenção da União, do poder público federal na questão ambiental nos Estados Unidos. Quem tem legitimação para exercê-lo são os Estados. Como regra, a União não detém o Poder de Polícia. A intervenção legislativa federal legitimar-se-á em outros pontos da Constituição Americana, tais como a cláusula de comércio, (commerce clause), no tocante ao comércio entre Estados. Da perspectiva da regulação ambiental, é difícil acreditar que a União, nos EUA, não tem Poder de Polícia. Assim, para fins internos e de aplicação das leis, para evitar a declaração de inconstitucionalidade de leis federais, os tribunais vêem com ampliação enorme a cláusula de comércio interestadual. Entretanto, para nós, que estamos fora dos EUA, parece que tudo é feito com base no Poder de Polícia.

A estrutura legal é, de certa maneira, bem parecida, pois em ambos os países há leis gerais, como a Lei da Política Nacional do Meio Ambiente, e leis específicas, seja, no caso brasileiro, o Código Florestal e a Lei de Proteção à Fauna e, no caso dos Estados Unidos, a Lei do Ar Puro ou a Lei das Águas Puras.

Passemos à organização institucional. Aqui também há algo extremamente interessante. Nos Estados Unidos, impera aquilo que denomino "pluralismo institucional", verificando-se dois tipos de pulverização: pulverização vertical e pulverização horizontal. Pulverização vertical porque temos a União, os Estados e, de certa maneira, os Municípios - na área de planejamento urbano (urban planning) com responsabilidades no campo ambiental. Os Estados, na verdade, nos Estados Unidos, representam um laboratório para a legislação federal. Vários dos institutos que são posteriormente legislados no plano federal foram testados ou, de certa maneira, antes de testados, criados, no âmbito dos estados-membros.

Também é importante notar que se discute muito, nos Estados Unidos - e essa expressão está presente na Constituição de 1988 do Brasil - em "federalismo de cooperação". O Clean Water Act (Lei das Águas Puras), por exemplo, usa este conceito de forma muito clara, e outras leis norte-americanas também. O que nós observamos, tanto lá como aqui, é que, na verdade, não existe um federalismo de cooperação, mas sim um federalismo de tensão. Não há cooperação, o que há, verdadeiramente, é um quadro de tensão permanente entre União, Estados e Municípios. No Brasil, não há 
esta fragmentação da mesma forma que nos Estados Unidos; há o que eu denominaria um certo "monismo institucional". Toda a área ambiental, por exemplo, no plano federal, está concentrada em um único órgão, que é o IBAMA? e, se quiserem, IBAMA e Ministério do Meio Ambiente. Não há esta fragmentação, de um lado entre os aspectos da regulação marrom do meio ambiente (controle da poluição) para um órgão, e a parte verde, para vários outros órgãos, como ocorre nos Estados Unidos. Então, eles sabem que a EPA (Agência Ambiental Americana) cuida especificamente, quase que exclusivamente, do controle da poluição. Toda a parte de proteção da natureza, no plano federal americano, está fragmentada entre vários Ministérios, que vão do Ministério do Interior (Departament of Interior) e seus vários órgãos, cuidando do meio ambiente, do Ministério da Agricultura e até em alguns Ministérios Militares, porque toda a parte de áreas úmidas, de manguezais (wetlands), tudo isso está sob controle e exige um licenciamento próprio do chamado "corps of engineering".

Ao tratar agora do licenciamento, já me encaminho para a parte final desta intervenção. O licenciamento ambiental é uma invenção norte-americana. Não havia licenciamento ambiental em outros países antes dos Estados Unidos ampliarem ou trazerem o conceito de licenciamento do direito administrativo e aplicarem esta noção especificamente na área do meio ambiente ${ }^{8}$.

Tanto no Brasil como nos Estados Unidos se utiliza o sistema das várias licenças. Em vez de uma única licença ambiental, nós temos uma licença ambiental, no caso dos Estados Unidos, para ar, outra para água, outra para atividades que afetem wetlands (áreas úmidas), resíduos tóxicos e perigosos, etc. No caso brasileiro, ocorre a mesma coisa, só que a licença para a parte do controle da poluição é uma só, e a licença para justificar ou, de certa maneira, legitimar atividades que afetem a natureza, na maioria dos Estados, também é única. Como regra, teríamos duas licenças ambientais no Brasil (às vezes, há Estados que têm outras); nos Estados Unidos, esse número de licenças é muito maior.

\footnotetext{
${ }^{7}$ Lei n. 6.938/81, art. 6, inciso IV. O IBAMA è fruto da fusão dos antigos IBDF, SUDEPE e SEMA. A SEMA (Secretaria Especial do Meio Ambiente) foi criada em 1973 pelo governo federal em resposta à polêmica e criticada participação do Brasil na Conferência de Estocolmo, em 1972, onde nossos representantes, aliados à China e Índia, apregoando a necessidade de crescimento a qualquer custo, expressaram ferrenha oposição à nascente política internacional de proteção ambiental.

${ }^{8}$ Como escrevemos no estudo apresentado sob o título Introdução ao Direito Ambiental Brasileiro, - licenciamento ambiental é novidade que aparece no Brasil no início da década de 70 , tanto mais quando o Estado de São Paulo, em 1976, promulgou sua legislação de controle da poluição (Lei $n$. 997, de 31.5.76). No plano federal, este só passa a ser exigido a partir de 1981, com a Lei da Política Nacional do Meio Ambiente (Lei n. 6.938/81). Atualmente, a matéria vem tratada em vários texto legais, bastando aqui citar a própria Lei n. 6.938/81 e as Resoluções CONAMA n.s 001/86 e 237/97.
} 
Nesse contexto do licenciamento, uma das maiores contribuições do Direito Norte-Americano para o Direito Comparado foi a criação do estudo prévio de impacto ambiental (o environment impact statement), estabelecido na Lei da Política Nacional do Meio Ambiente dos Estados Unidos'. E aqui nós percebemos como o Direito Comparado não é só comparado. Direito Comparado é um esforço, na verdade, de criação de Direito, de modificação legislativa pela comparação. Nós não nos limitamos a importar modelos. Apesar deste instituto ser criação do Direito Norte-Americano, ele foi profundamente transformado pelo Direito Comparado, tornando-se melhor neste do que no sistema norte-americano.

Vamos ver por que isso ocorre e por que eu faço esta afirmação. Primeiro porque, nos Estados Unidos, o estudo prévio de impacto ambiental é exigido, fundamentalmente, quando não exclusivamente, para empreendimentos que possam ter impacto significativo no meio ambiente e que sejam decorrência de uma ação estatal. Vale dizer, como regra, não se exige o estudo de impacto ambiental para as atividades e os projetos exclusivamente privados. É verdade que este conceito de ação estatal, no caso da legislação federal americana (the federal act), vem sendo ampliado para incluir, por exemplo, ou para dar o tom de ação federal a um empreendimento pelo simples fato de que o projeto recebe $10 \%$ de financiamento de uma agência ou de um banco, mesmo que privado, mas com fundos públicos. Em alguns casos, para dizer até que, se há necessidade de licenciamento ambiental, isto poderia ser considerado como ação estatal e, por isso, esse empreendimento se submeteria ao estudo prévio de impacto ambiental. No Brasil, o sistema é bastante diferente porque, embora tenhamos importado a concepção de estudo prévio de impacto ambiental dos Estados Unidos, nós, já de imediato, a partir de 1981, modificamos profundamente o seu desenho estrutural ${ }^{10}$.

Primeiramente, no Brasil, ao contrário do que ocorre nos Estados Unidos, o estudo prévio de impacto ambiental é exigido de qualquer empreendimento, público ou privado. Público inteiramente por meio público - o único requisito é que este empreendimento possa ter um impacto significativo no meio ambiente ${ }^{11}$. Não se exclui nem sequer as atividades militares, enquanto que nos Estados Unidos e na Diretiva da União Européia, as atividades militares são expressamente excluídas. No caso do Brasil,

\footnotetext{
${ }^{9}$ Hoje, no mundo inteiro, o Estudo Prévio de Impacto Ambiental (EPIA) é considerado um dos instrumentos jurídicos imprescindíveis à proteção do ambiente. Seus objetivos - todos colimando um maior controle da álea discricionária da Administração Pública ambiental - são diversos e multifacetários, podendo ser classificados em quatro categorias principais: a) prevenção (e até precaução) do dano ambiental; b) transparência administrativa quanto aos efeitos ambientais de empreendimentos públicos ou privados; c) consulta aos interessados; e d) decisões administrativas informadas e motivadas.

${ }^{10}$ Nos termos da Resolução n. 001/86, "considera-se impacto ambiental qualquer alteração das propriedades físicas, químicas e biológicas do meio ambiente, causada por qualquer forma de matéria ou energia resultante das atividades humanas que, direta ou indiretamente, afetam: I - a saúde, a segurança e o bem-estar da população; II - as atividades sociais e econômicas; III - a biota; IV - as condições estéticas e sanitárias do meio ambiente; $V$ - a qualidade dos recursos ambientais".

${ }^{11} \mathrm{O}$ EPIA é elaborado sempre que presente a potencialidade de significativa degradação do meio ambiente. Estamos ai diante de conceito jurídico indeterminado que não é (nem poderia ser) definido pelo legislador mediante equação matemática (= numerus clausus).
} 
o estudo de impacto ambiental tem caráter substantivo e não meramente procedimental. E talvez seja essa a maior alteração de fundo que implementamos no ordenamento jurídico ou no modelo jurídico que importamos desse esboço de Direito Comparado dos Estados Unidos. Ou seja, para nós, brasileiros, o estudo de impacto ambiental é uma ferramenta que vai não apenas orientar a decisão administrativa, mas é uma ferramenta que vai determinar a decisão administrativa.

Assim nos Estados Unidos o estudo de impacto ambiental é meramente procedimental, vale dizer, o que se quer é que um estudo interdisciplinar seja feito e que, com isso, o órgão público - que vai tomar a decisão - possa estar bem informado sobre o quadro global dos impactos deste empreendimento no meio ambiente. Mas ele pode decidir, inclusive, de forma contrária ao estudo de impacto ambiental. No Brasil, o poder público tem que se limitar à melhor solução apontada pelo estudo de impacto ambiental. Talvez seja esse um daqueles bons exemplos de trabalho adequado de Direito Comparado, em que buscamos uma idéia do outro sistema jurídico, trabalhamos essa idéia, e chegamos a melhorar este instrumento, adequado às nossas possibilidades.

Por último, gostaria de falar da responsabilidade civil e da implementação. No campo da responsabilidade civil, quantas vezes não atentamos para este aspecto? $\mathrm{O}$ Brasil possui, para o dano ambiental, um dos regimes mais completos do mundo. E é completo, ou é moderno, porque ele prevê, a um só tempo, um quadro estrutural - que nós poderíamos denominar de fundo - muito avançado. Mas, ao mesmo tempo, o ordenamento jurídico brasileiro montou um conjunto de instrumentos de acesso à justiça que viabilizam estes novos direitos e obrigações estabelecidas no plano do direito material. Mas vamos nos limitar aqui apenas aos aspectos de direito material da responsabilidade civil e comparar com o modelo norte-americano.

No Brasil, a regra, sem exceção, para o dano ambiental, é da responsabilidade civil objetiva (strict liability) ${ }^{12}$. E é um modelo extremamente amplo. Eu não conheço precedentes do Direito Comparado, especialmente do Direito Comparado europeu, porque ele se aplica tanto à área marrom (ao direito ambiental de controle da poluição) como à área verde (ao direito ambiental de proteção da natureza). Por exemplo: no Brasil, tanto faz um acidente com uma substância tóxica numa indústria que venha a destruir a fauna de um lago ou de um curso d'água, como um incêndio numa floresta, onde o fazendeiro pôs fogo no capim, perdeu o controle, e a floresta, mesmo não sendo uma área protegida, como unidade de conservação, venha a ser destruída. Nos dois casos, não vamos perguntar se o responsável ou sé o causador agiu com culpa: é caso de responsabilidade civil objetiva. Além disso, é interessante notar que é um sistema não apenas de responsabilidade civil objetiva, mas de responsabilidade civil objetiva

\footnotetext{
${ }^{12}$ Em termos de responsabilidade civil, dispõe a Lei da Política Nacional do Meio Ambiente que "é o poluidor obrigado, independentemente de existência de culpa, a indenizar ou reparar os danos causados ao meio ambiente e a terceiros, afetados por sua atividade". Trata-se, pois, de responsabilidade civil objetiva, tanto no que se refere a prejuizos pessoais (patrimoniais e morais), chamados, na diç̧ão da lei, de "danos causados a terceiros", como na hipótese de dano ambiental puro ("danos causados ao meio ambiente").
} 
solidária. Novamente, separamo-nos do sistema norte-americano, que prevê a responsabilidade civil solidária em alguns casos, especialmente no caso do Super Fund (Super Fundo), mas não tem isso como uma regra geral.

Para concluir, tratemos da implementação, mais especificamente, do que nos separa do modelo norte-americano e de como poderíamos, de certa maneira, em uma palavra, dizer ou mencionar as diferenças ou similitudes entre os dois sistemas.

A primeira diferença fundamental é de que não há nos Estados Unidos nada que se assemelhe ao Ministério Público brasileiro. Eles têm três Ministérios Públicos, nós temos dois. Os americanos têm o Ministério Público Federal, que é ligado ao Ministro da Justiça, que é um Ministro como qualquer outro e que não é vitalício, quer dizer, não tem a garantia da vitaliciedade. De outra parte, o Ministério Público Estadual é o segundo Ministério Público, e eles ainda têm o Ministério Público da Comarca (County). A maioria dos ilícitos penais ambientais é levada aos Tribunais pelo Ministério Público da Comarca (County). E os três são independentes. A segunda grande diferença entre os Ministérios Públicos é que o Ministério Público Federal não é eleito, mas, como já disse, não é vitalício, e o Procurador-Geral do Estado e o Promotor de Justiça são, normalmente, eleitos.

No plano da implementação (enforcement), o que mais chama a atenção é que a grande maioria das ações coletivas é proposta não pelo Ministério Público, mas por indivíduos que representam uma classe, por meio de instituições, ou por Organizações não Governamentais, que representam estes interesses específicos (environment groups). Nos Estados Unidos como no Brasil, temos a possibilidade de utilização de uma ação para fins reparatórios, que eles chamam de Class Action, e nós chamamos de Ação Civil Pública ${ }^{13}$. Lá, atualmente, também há a possibilidade do cidadão individualmente entrar com uma ação para obrigar o órgão público a fazer algo ou a deixar de fazer; eles chamam esse instrumento de Citizen Suit, e nós chamamos, também, de Ação Civil Pública. Logo, a nossa Ação Civil Pública é, a um só tempo, ou corresponde, a um só tempo, a Class Action norte-americana e a Citizen Suit, que é prevista, especificamente, em várias das leis promulgadas naquele País.

\footnotetext{
${ }^{13}$ Embora consagrada, a denominação ação civil pública é, em rigor terminológico, inadequada. A um, porque, no plano dos legitimados, a ação nem sempre é pública, porquanto ONGs, de caráter privado, estão habilitadas a utilizá-la. A dois, porque tampouco é exclusivamente público o interesse tutelado, já que o dano ambiental lato sensu pode apresentar conteúdo difuso, coletivo stricto sensu ou individual homogêneo.
} 